\title{
Pharmacological mechanisms involved in the analgesia induced by ethanol extract of Hybanthus enneaspermus leaves
}

This article was published in the following Dove Press journal: Journal of Pain Research

2I August 2017

Number of times this article has been viewed

\author{
Ayobami Oladele Afolabi' \\ Isiaka Abdullateef \\ Alagbonsi ${ }^{2}$ \\ Jubril Ayodeji Aliyu'
}

'Department of Physiology, College of Health Sciences, Ladoke Akintola University of Technology, Ogbomoso, Nigeria; ${ }^{2}$ Department of Physiology, Faculty of Medicine and Health Sciences, University of Gitwe, Gitwe, Republic of Rwanda

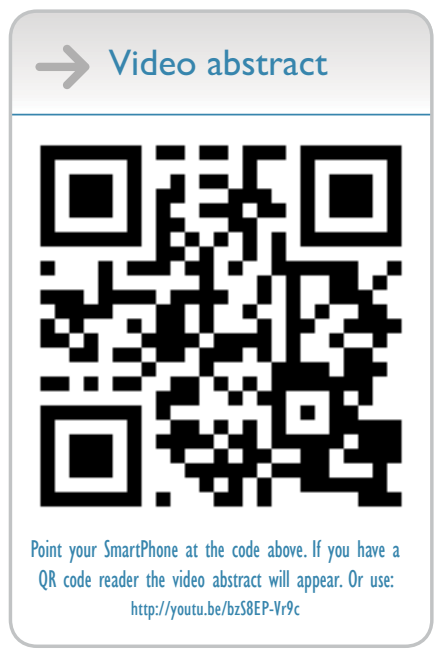

Correspondence: Isiaka Abdullateef Alagbonsi

Department of Physiology, Faculty of Medicine and Health Sciences, University of Gitwe, Gitwe, PO Box I Nyanza, Ruhango District, Southern Province, Republic of Rwanda

Tel +250725 300424

Email easylat@gmail.com
Background: Hybanthus enneaspermus (HE) leaves are being used traditionally to relieve pain, and scientific studies have demonstrated their analgesic potential. This study attempted to elucidate the pharmacological mechanism(s) involved in the analgesic action of ethanol extract of H. enneaspermus leaves (EEHE).

Materials and methods: Forty-two male Wistar rats were separately randomized into seven groups ( $\mathrm{n}=6$ rats in each group) for tail immersion and formalin tests. Group I (control) received distilled water $(10 \mathrm{~mL} / \mathrm{kg}$ ) while groups II and III received acetaminophen (the reference drug, $100 \mathrm{mg} / \mathrm{kg}$ ip) and EEHE (1000 mg/kg po), respectively. Groups IV-VII were pretreated with cimetidine (50 mg/kg ip), naloxone ( $5 \mathrm{mg} / \mathrm{kg} \mathrm{ip})$, propranolol $(0.15 \mathrm{mg} / \mathrm{kg}$ ip), and prazosin $(0.15 \mathrm{mg} / \mathrm{kg}$ ip), respectively, 1 hour before EEHE $(1000 \mathrm{mg} / \mathrm{kg} \mathrm{po})$ treatment.

Results: The EEHE-induced increase in tail-flick latency was reduced by blockade of histamine and adrenergic receptors but prevented by blockade of opiate receptor in the tail-flick test. However, the EEHE-induced decrease in paw licking time was prevented only by blockade of opiate receptor but unaffected by histamine and adrenergic receptors blockers.

Conclusion: These findings suggest that the analgesic effect of EEHE in different pain types may involve different neural mechanisms and that the opioidergic pathway contributes more to EEHE-induced analgesia than the other pathways.

Keywords: analgesia, formalin test, Hybanthus enneaspermus, pain, tail immersion test

\section{Introduction}

Owing to poor treatment outcomes from orthodox medical therapies, patients are increasingly turning to complementary and alternative medicine (CAM) for the relief of pain-related conditions. ${ }^{1} \mathrm{CAM}$ has been used to bring relief in lieu of or as an adjunct to conventional medical therapies. Clinical observations have shown that herbal remedies relieve cancer pain and other forms of pain in more than half of their users. ${ }^{2-4}$

The use of herbal medicine, an ancient form of treatment known to man, is common to all peoples and cultures. ${ }^{5}$ For instance, there is a history of lifetime use of CAM by $30 \%-60 \%$ and $47 \%$ of the population of $\mathrm{USA}^{6,7}$ and $\mathrm{UK}^{8}{ }^{8}$ respectively, while $10 \%$ of hospital physicians in the UK use it as part of their clinical practice. ${ }^{9}$ High-quality researches into the efficacy of herbal medicine are relatively few compared to the growing worldwide interest in it. Moreover, the efficacy, safety, and toxicity of some herbs being used in the relief of chronic pain and the analgesic mechanisms involved remain unclear. ${ }^{4,10}$ 
Many herbs and vegetables derive their local names from their speculated actions on the human body. For instance, Hybanthus enneaspermus leaves are known as "ēwé ābíwéré" in Yoruba language (meaning a leaf that induces painless or fast delivery or both during labor) because of their widespread ethnopharmacological use as a traditional analgesic herb, especially to reduce labor pain in pregnant women. ${ }^{11}$ While Awobajo et al ${ }^{12}$ demonstrated the uterotonic effect of their aqueous extract in isolated uterine muscles of pregnant rats, Afolabi et $\mathrm{al}^{11}$ demonstrated the dose-dependent antinociceptive effect of their ethanol extract in male Wistar rats. Phytochemical screening of $H$. enneaspermus leaves extract ${ }^{13}$ has shown that the leaves contain saponins, tannins, and flavonoids, which are known to have analgesic effect in animals. ${ }^{14,15}$ Afolabi et $\mathrm{al}^{11}$ speculated that the anti-nociceptive effect exhibited by the ethanol extract of $H$. enneaspermus leaves (EEHE) might be due to the synergistic action of its phytochemical components. However, the pharmacological mechanisms involved in the analgesic action of the leaves have not been determined. We investigated the involvement of histamine, opioid, and adrenergic receptors in the EEHEinduced analgesia using the tail immersion and formalin tests.

\section{Materials and methods Animals}

Numerous studies have reported sex differences in pain perception, with lower pain thresholds and tolerance in females than in males. However, there have been conflicting reports on the modulation of nociception by estradiol, as both hypoalgesia $^{16,17}$ and hyperalgesia ${ }^{18}$ have been associated with it, in addition to the reported effect of estrous cycle on nociception in female rats. ${ }^{19,20}$ Therefore, we opted to use male rats for the investigation of the mechanisms involved in the antinociceptive effect of $H$. enneaspermus leaves in this study.

Male Wistar rats $(140 \pm 20 \mathrm{~g})$ used for this study were obtained from the Institute of Medical Research and Training, University of Ibadan College Hospital, Nigeria; they were housed at room temperature with unrestricted access to food and tap water and maintained on a daily light/dark cycle. In addition to experimental protocol approval by the research ethics committee of the College of Health Sciences, Ladoke Akintola University of Technology, Ogbomoso, Nigeria, "principles of laboratory animal care (NIH publication No. 85-23, revised 1985)" were followed.

\section{Preparation of EEHE}

Hybanthus enneaspermus leaves were bought from a farmer at Owode market in Ogbomoso, Oyo, Nigeria, and authenticated by Mr KA Adeniji of the Forestry Research Institute of Nigeria, Ibadan, where a specimen voucher number FHI 1008871 was deposited. They were ground into a moderately coarse powder (using pestle and mortar) after air-drying them in a well-ventilated and shaded room. About $170 \mathrm{~g}$ of the dried powder was then extracted with $95 \%$ ethanol for 72 hours using the Soxhlet apparatus as previously described. ${ }^{21} \mathrm{~A}$ semisolid extract (10.2 g, 6\%) was obtained by evaporating ethanol with a rotary evaporator and then refrigerated until further use.

\section{Experimental protocol}

Tail immersion test

Forty-two male rats were randomized into seven treatment groups ( $n=6$ rats in each group). Group I (control) received distilled water $(10 \mathrm{~mL} / \mathrm{kg})$ while groups II and III received acetaminophen (the reference drug, $100 \mathrm{mg} / \mathrm{kg}$ ip) and EEHE (1000 mg/kg po), ${ }^{11}$ respectively. Groups IV-VII were pretreated with cimetidine $\left(50 \mathrm{mg} / \mathrm{kg}\right.$ ip) ${ }^{22}$ naloxone $(5 \mathrm{mg} / \mathrm{kg}$ ip), ${ }^{23}$ propranolol $(0.15 \mathrm{mg} / \mathrm{kg}$ ip $),{ }^{24}$ and prazosin $(0.15 \mathrm{mg} / \mathrm{kg}$ ip), ${ }^{25}$ respectively, 20 minutes before EEHE (1000 mg/ $\mathrm{kg} \mathrm{po}$ ) treatment. The tail immersion test was performed 1 hour after the final treatment.

Animals were handled for 3 minutes and habituated to the testing room for 1 hour on two occasions before the day of testing and again on the day of testing. Each rat was removed from its home cage and gently restrained in a towel, and $\sim 5 \mathrm{~cm}$ of its tail from the tip was immersed in a water bath $\left(52 \pm 0.5^{\circ} \mathrm{C}\right)$ in order to determine the tail-flick latency (TFL) period. The TFL period, recorded by stopwatch, ${ }^{26}$ is the time (in seconds) taken for the animal to clearly withdraw or flick its tail out of the water.

\section{Formalin test}

Another 42 male rats were randomly divided into seven groups ( $n=6$ rats in each group) as stated earlier for the tail immersion test. Animals were habituated to the $30 \mathrm{~cm}^{3}$ transparent Plexiglas observation box for 30 minutes on two occasions before the day of testing and immediately before testing. Each rat was removed from the observation box and restrained in a towel, followed by drug(s) treatment according to the treatment group. Then 1 hour after the final treatment, $0.05 \mathrm{~mL}$ of $2.5 \%$ formalin was injected into the plantar surface of the left hind paw of the animal. The animal was then returned into the glass chamber for observation. The time spent licking or biting the paw during the first 5 minutes and 15-30 minutes of formalin injection represents the early and late phases of the nociceptive response, respectively. ${ }^{27}$ The 
circadian effects on nociceptive and analgesic sensitivity ${ }^{28}$ were minimized by conducting all the tests between 10:00 am and 4:00 pm.

\section{Statistical analysis}

Data were analyzed with one-way analysis of variance using SPSS version 16.0 (IBM Corporation, Armonk, NY, USA), followed by a post hoc Tukey test for multiple comparisons and expressed as mean \pm SEM. $p$-Values $\leq 0.05$ were considered statistically significant.

\section{Results}

\section{Opioidergic pathway contributes more while histamine and adrenergic pathways contribute less to EEHE-induced analgesia}

The TFL in rats that received acetaminophen $(5.12 \pm 0.23$ seconds) and EEHE (5.33 \pm 0.56 seconds) were comparable $(p>0.05)$ but higher $(p<0.05)$ than in the control $(2.93 \pm 0.25$ seconds). The EEHE-induced increase in TFL was reduced by pretreatment with cimetidine ( $4.38 \pm 0.19$ seconds), propranolol (4.23 \pm 0.21 seconds), and prazosin ( $4.43 \pm 0.21$ seconds) but prevented by pretreatment with naloxone $(3.75 \pm 0.48$ seconds $)(F$-test $=10.48, p<0.0001$; Figure 1$)$.

\section{Opioidergic pathway is involved in EEHE- induced anti-inflammatory activity}

During the early phase of the formalin test, the paw licking time (PLT) in rats that received acetaminophen

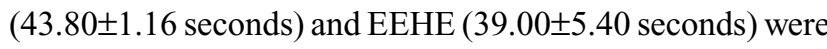
also comparable $(p>0.05)$ but lower $(p<0.05)$ than the control (60.83 \pm 3.24 seconds). The EEHE-induced reduction in the PLT was prevented $(p<0.05)$ by pretreatment with naloxone (58.33 \pm 4.67 seconds) but unaffected $(p>0.05)$ by pretreatment with cimetidine (35.50 \pm 6.10 seconds), propranolol

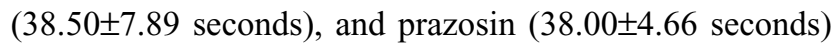
$(F$-test $=11.49, p<0.0001 ;$ Figure $2 \mathrm{~A})$.

During the late phase, however, there was more noticeable reduction $(p<0.05)$ in the PLT by EEHE $(92.83 \pm 10.45 \mathrm{sec}-$ onds) than acetaminophen ( $125.50 \pm 6.99$ seconds) when compared to control (160.50 \pm 8.23 seconds). Similar to the pattern observed during the early phase, the EEHE-induced reduction in the PLT was prevented $(p<0.05)$ by pretreatment with naloxone (156.20 \pm 8.06 seconds) but unaffected $(p>0.05)$ by pretreatment with cimetidine ( $88.80 \pm 5.49$ seconds), propranolol

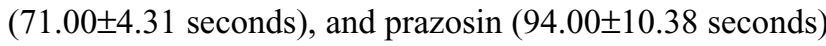
$(F$-test $=26.48, p<0.0001$; Figure $2 B)$.

\section{Discussion}

Large numbers of receptor systems, including opioid, histaminergic, cholinergic, adrenergic, and glutaminergic systems, have been reported to be involved in nociception of many herbs. ${ }^{29}$ While some of these receptor systems mediate nociception centrally, others mediate it peripherally. ${ }^{30}$ We have suggested that the anti-nociceptive action of EEHE is both centrally- and peripherally-mediated. ${ }^{11}$ The present study validates our previously reported anti-nociceptive effect of EEHE and provides additional information that opioidergic pathway greatly contributes to EEHE-induced analgesia during both TFL and formalin tests, while histaminergic and adrenergic pathways also partly contribute to it during the tail-flick test only but not during the formalin test.

The models of nociception selected for this study are such that both centrally- and peripherally-mediated effects were assessed. While the TFL test assessed centrally-mediated thermal nociception, ${ }^{31}$ the formalin-induced paw licking test assessed the centrally-mediated but chemically-induced nociception and the peripherally-mediated inflammatory nociception. ${ }^{32}$ The tail-flick test, which is a brief, rapid pain, is a reflex to noxious stimulation that is mediated by spinal cord

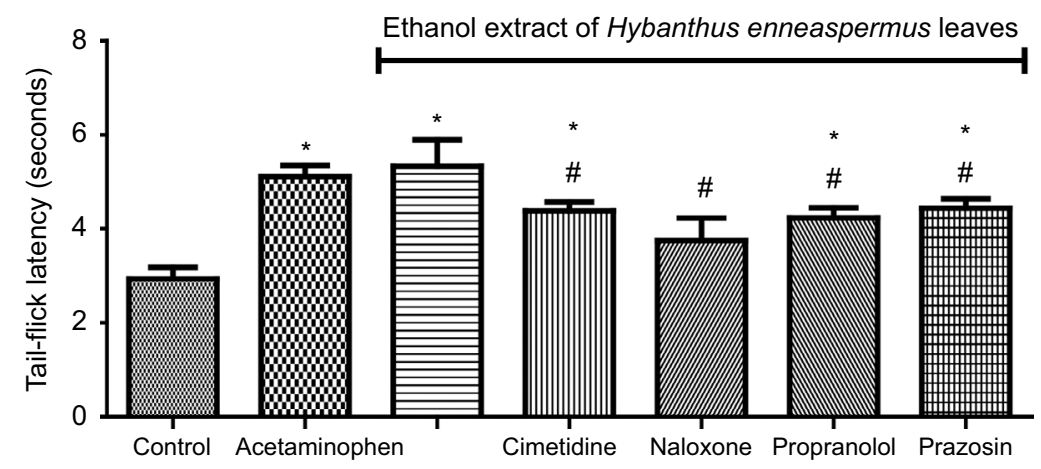

Figure I Role of histamine, opioid, and adrenergic receptors in ethanol extract of Hybanthus enneaspermus leaves-induced increase in tail-flick latency.

Notes: ${ }^{*} p<0.05$ vs control, $" p<0.05$ vs ethanol extract of $H$. enneaspermus leaves (cimetidine $=$ histamine receptor blocker, naloxone $=$ opioid receptor blocker, propranolol $=$ beta adrenoceptor blocker, prazosin = alpha adrenoceptor blocker). 


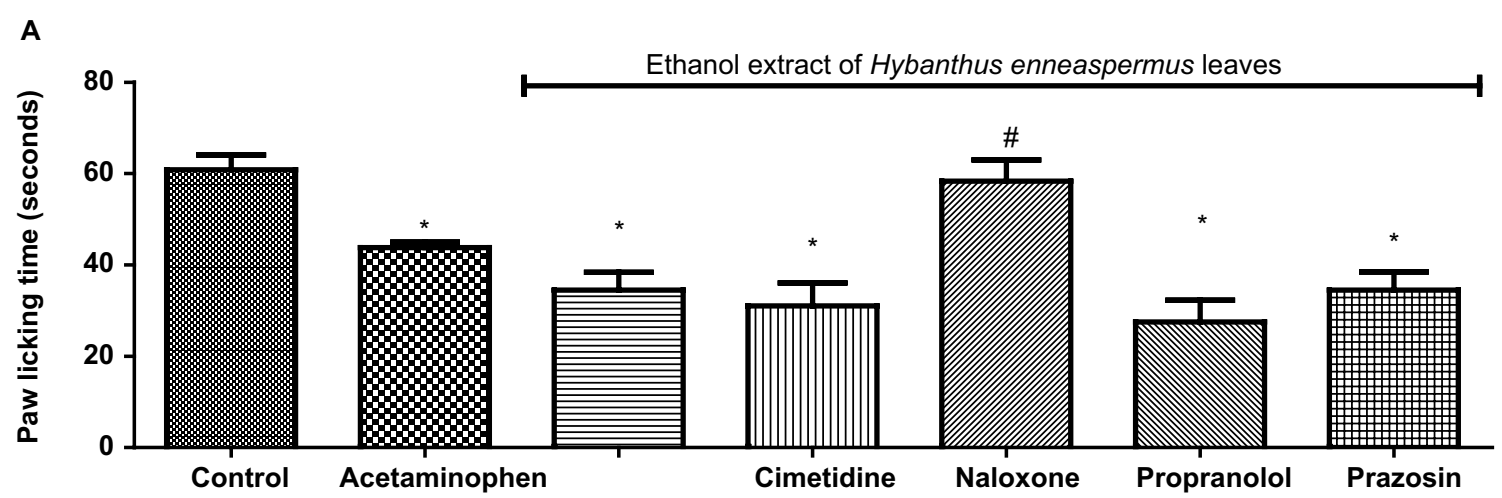

B

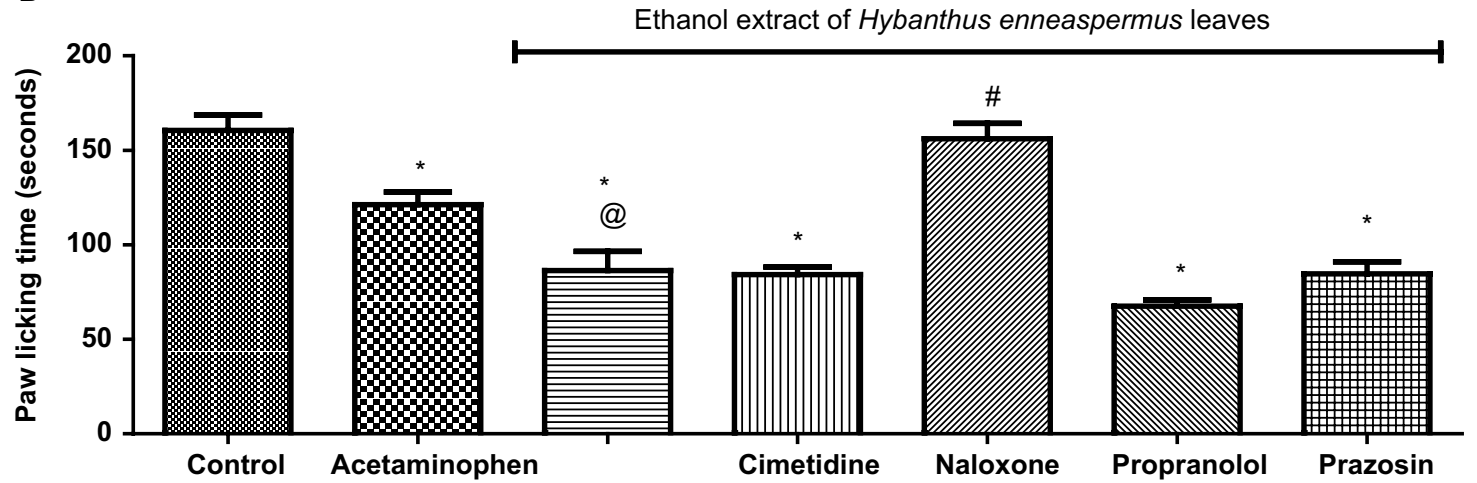

Figure 2 Role of histamine, opioid, and adrenergic receptors in ethanol extract of Hybanthus enneaspermus leaves-induced decrease in the paw licking time of rats during the early $(\mathbf{A})$ and late $(\mathbf{B})$ phases of formalin test.

Notes: Values are expressed as mean \pm SEM ( $n=6$ ); $p<0.05$ vs control, ${ }^{@} p<0.05$ vs acetaminophen, ${ }^{*} p<0.05$ vs ethanol extract of Hybanthus enneaspermus leaves (cimetidine $=$ histamine receptor blocker, naloxone $=$ opioid receptor blocker, propranolol = beta adrenoceptor blocker, prazosin $=$ alpha adrenoceptor blocker).

Abbreviation: SEM, standard error of the mean.

and results in tail withdrawal at the lowest possible threshold for pain. The formalin test, by contrast, is a prolonged, steady pain which measures the response to a long-lasting nociceptive stimulus and, therefore, resembles clinical pain. ${ }^{32}$ The early phase is thought to act by direct chemical stimulation of nociceptors, ${ }^{33}$ while the late phase response acts through inflammation ${ }^{34}$ mediated by histamine, serotonin, and prostaglandins. ${ }^{30}$ Centrally acting drugs like narcotics inhibit both phases of formalin-induced pain, while peripherally acting drugs such as aspirin only inhibit the late phase. ${ }^{29}$

Some differences in the pattern of results obtained from brief or phasic pain test (e.g., tail-flick and hot plate tests) and the prolonged or steady pain (e.g., formalin test) have been documented. For instance, morphine analgesia was unaffected by adrenergic blockers in the tail-flick and hot plate tests but was strikingly antagonized by them in the formalin test. ${ }^{35}$ Also, morphine analgesia that was decreased by anti-serotonergic drugs in the tail-flick test was otherwise increased in the formalin test. ${ }^{36}$ In this study, histamine and adrenergic receptors (alpha and beta) were involved in the EEHE-induced analgesia in the brief pain (TFL test) but were not involved in the prolonged or steady pain (formalin test). This observation is similar to the previously reported differences in the neuronal pathways involved in the morphine-induced analgesia following thermal and chemical pain assessed by tail-flick and formalin tests, respectively. ${ }^{37}$ Our data thus support the contention that different analgesiaproducing systems are involved in different pain tests.

Narcotic analgesics act by binding to opiate receptors in the midbrain periaqueductal gray matter. The binding leads to the suppression of responses of the spinal neurons to noxious stimuli by the activated descending brain stem inhibitory systems. ${ }^{37}$ The present study suggests that administration of EEHE caused partial inhibition of nociception via the histaminergic and noradrenergic mechanisms but almost complete inhibition of nociception via the opioidergic pathway.

Previous studies have shown the presence of opiate receptors in the endothelium, ${ }^{38}$ sympathetic fibers, ${ }^{39,40}$ leukocytes, ${ }^{40,41}$ and peripheral afferent fibers, ${ }^{42,43}$ all of which are involved in inflammation. The stimuli for the early and late phases of the formalin test have been shown to be different, as that of the former is a direct chemical stimulation of the nociceptors 
while the latter involves inflammation. ${ }^{30,44}$ An observation of abolishment of the centrally mediated and peripherally mediated anti-nociceptive effect of EEHE by opiate receptor blocker (naloxone) not only suggests the involvement of opioidergic pathway in its analgesic action but also shows a possibility of the presence of opiate-like substances in EEHE.

\section{Conclusion}

This study provides information on the pharmacological mechanisms involved in EEHE-induced analgesia. It suggests that the analgesic effect of EEHE in different pain types may involve different neural mechanisms. It further shows that the histamine and adrenergic pathways partly contribute to the EEHE-induced analgesia during the centrally-mediated thermal but not chemical pain and peripherally-mediated inflammatory pain, while the opioidergic pathway plays a predominant role during both centrally- and peripherallymediated pain types.

\section{Author contributions}

All authors contributed toward data analysis, drafting and critically revising the paper and agree to be accountable for all aspects of the work.

AOA and IAA are the first/lead authors.

\section{Disclosure}

The authors report no conflicts of interest in this work.

\section{References}

1. Cauffield JS. The psychosocial aspects of complementary and alternative medicine. Pharmacotherapy. 2000; 20:1289-1294.

2. Eisenberg DM, Davis RB, Ettner SL, et al. Trends in alternative medicine use in the United States, 1990-1997: results of a follow-up national survey. JAMA. 1998;280:1569-1575.

3. Rao JK, Mihaliak K, Kroenke K, Bradley J, Tierney WM, Weinberger M. Use of complementary therapies for arthritis among patients of rheumatologists. Ann Intern Med. 1999;131:409-416.

4. Rosenberg EI, Genao I, Chen I, et al. Complementary and alternative medicine use by primary care patients with chronic pain. Pain Med. 2008;9:1065-1072.

5. Lewith GT, Breen A, Filshie J, et al. Complementary medicine: evidence base, competence to practice and regulation. Clin Med.2003;3:235-240.

6. Astin J. Why patients use alternative medicine: results of a national survey. JAMA. 1998;279:1548-1553.

7. Barnes PM, Powell-Griner E, McFann K, Nahin RL. Complementary and Alternative Medicine Use Among Adults: United States 2002. Advance data from vital and health statistics, no. 343. Hyattsville (MD): National Center for Health Statistics; 2004.

8. Thomas K, Nicholl JP, Coleman P. Use and expenditure on complementary medicine in England. Complement Ther Med. 2001;9:2-11.

9. Lewith GT, Hyland M, Gray SF. Attitudes to and use of complementary medicine among physicians in the United Kingdom. Complement Ther Med. 2001;9:167-72.

10. Xu L, Lao LX, Ge A, Yu S, Li J, Mansky PJ. Chinese herbal medicine for cancer pain. Integr Cancer Ther. 2007;6:208-234.
11. Afolabi AO, Oluwakanmi ET, Salahdeen HM, Oyekunle AO, Alagbonsi IA. Anti-nociceptive effect of ethanolic extract of Hybanthus enneaspermus leaf in rats. Br J Med Med Res. 2014;4:322-330.

12. Awobajo FO, Adegoke OA, Iranloye BO, Olatunji-bello II. Experimental evaluation of the impact of maternal consumption of aqueous leaf extract of Hybanthus enneaspermus on pregnancy in Sprague Dawley rats. Afr J Tradit Complem Altern Med. 2013;10:283-291.

13. Awobajo FO, Olatunji-Bello II, Adegoke OA, Odugbemi TO. Phytochemical and antimicrobial screening of Hybanthus enneaspermus and Paquentina nigricense. Recent Res Sci Technol. 2009;1:159-160.

14. Bittar M, De Souza MM, Yunes RA, Lento R, Delle MF, Cechinel FV. Anti-nociceptive activity of 13,118-binaringenin, a biflavonoid present in plants of the guttiferae. Plant Medic. 2000;66:84-86.

15. Ramaswamy S, Pillai NP, Gopaallershnan V, Parmar NS, Gosh MN. Analgesic effect of $\beta$ Hydroxyl ethyl nitroside in mice. Indian J Exp Biol. 1985;23:219-220.

16. Stoffel EC, Ulibarri CM, Craft RM. Gonadal steroid hormone modulation of nociception, morphine anti-nociception and reproductive indices in male and female rats. Pain. 2003; 103:285-302.

17. Walf AA, Frye CA. Anti-nociception following exposure to trimethylthiazoline, peripheral or intra-amygdale estrogen and/or progesterone. Behav Brain Res. 2003;144:77-85.

18. JiY, Murphy AZ, Traub RJ. Estrogen modulation of morphine analgesia of visceral pain in female rats is supraspinally and peripherally mediated. J Pain. 2007;8:494-502.

19. Martinez-Gomez M, Cruz Y, Salas M, Hudson R, Pacheco P. Assessing pain threshold in the rat: changes with estrus and time of day. Physiol Behav. 1994;55:651-657.

20. Molina N, Bedran-De-Castro MTB, Bedran-De-Castro JC. The role of opioids in the analgesic response of rats during the estrous cycle. Braz J Med Biol Res. 1990;23:1157-1159.

21. Tripathy S, Sahoo SP, Pradhon D, Sahoo S, Satapathy DK. Evaluation of antiarthritic potential of Hybanthus enneaspermus. Afr J Pharm Pharmacol. 2009;3:611-614.

22. Oluwole FS, Onasanwo SA, Olaleye SB. Effects of aqueous and methanolic extracts of Persea americana leaf (Avocado pear) on gastric acid secretion in male albino rats. Eur J Scient Res. 2011;61:474-481.

23. Duman EN, Kesim M, Kadioglu M, Yaris E, Kalyoncu NI, Erciyes N. Possible involvement of opioidergic and serotonergic mechanisms in antinociceptive effect of paroxetine in acute pain. $J$ Pharmacol Sci. 2004;94:161-165.

24. Oyadeyi AS, Ajao FO, Ibironke GF, Afolabi AO. Acute restraint stress induces hyperalgesia via non-adrenergic mechanisms in rats. Afr $J$ Biomed Res. 2005;8:123-125.

25. Mantovani M, Pertile R, Calixto JB, Santos ARS, Rodrigues ALS. Melatonin exerts an antidepressant-like effect in the tail suspension test in mice: evidence for involvement of N-methyl-D-aspartate receptors and the L-arginine-nitric oxide pathway. Neurosci Lett. 2003;343:1-4.

26. D'Amour FE, Smith DL. A method for determining loss of pain sensation. J Pharmacol Exp Ther. 1941;72:74-78.

27. Hunskar S, Hole K. The formalin test in mice: dissociation between inflammatory and non-inflammatory pain. Pain. 1987;30:103-114.

28. Castellano C, Puglisi-Allegra S, Renzi P, Oliverio A. Genetic differences in daily rhythms of pain sensitive in mice. Pharmacol Biochem Behavior. 1985;23:91-92.

29. Odoma S, Zezi AU, Danjuma NM, Ahmed A, Magaji G. Elucidation of the possible mechanism of analgesic actions of butanol leaf fraction of Olax subscorpioidea oliv. J Ethnopharmacol. 2017;199:323-327.

30. Shibata M, Ohkubo T, Takahashi H, Inoki R. Modified formalin test, characteristic biphasic pain response. Pain. 1989;38:347-352.

31. Dubussion R, Dennis SG. Pain signaling systems in the dorsal and ventral spinal cord. Pain. 1977;4:97-132.

32. Murray CW, Porreca F, Corvan A. Methodological refinement to the mouse paw formalin test: an animal model of tonic pain. J Pharmacol Methods. 1988;20:175-186.

33. Dubussion R, Dennis SG. Pain signaling systems in the dorsal and ventral spinal cord. Pain. 1977;4:97-132. 
34. Oyadeyi AS, Afolabi AO, Ajao FO, Ibironke GF. Reduced formalin nociceptive responses in a rat model of post-surgical pain. Am-Eur $J$ Sci Res. 2007;2:29-32.

35. Dennis SG, Melzack R, Gutman S, Boucher F. Pain modulation by adrenergic agents and morphine as measured by three pain tests. Life Sci. 1980;26:47-59.

36. Dennis SG, Melzack R. Pain modulation by 5-hydroxytryptaminergic agents and morphine as measured by three pain tests. Exp Neurol. 1980;69:260-270.

37. Abbott FV, Melzack R, Samuel C. Morphine analgesia in the tail-flick and formalin pain tests is mediated by different neural systems. Exp Neurol. 1982;75:644-651.

38. Yamamoto Y, Hotta K, Matsuda T. Effect of metenkephalin on the spontaneous activity of the smooth muscle of the rat portal vein. Life Sci. 1984;34:993-999.
39. Cairnie A, Kosterlitz H, Taylor D. Effect of morphine on some sympathetically innervated effectors. Br J Pharmacol. 1961;17:539-551.

40. Ramme D, Illes P, Spath L, Starke K. Blockade of alpha-2-adrenoceptors permits the operation of otherwise silent kappa receptors at the sympathetic axons of rabbit jejuna arteries. Naunyn Schmiedebergs's Arch Pharmacol. 1986;334:48-55.

41. Boogaer M, Vermylen J, Deckmyn H, et al. Enkephalins modify granulocyte-endothelial interactions by stimulating prostacyclin production. Thromb Hemost. 1983;50:572-575.

42. Fields HL, Emson P, Leigh B, Gilbert R, Iversen LL. Multiple opiate receptor sites on primary afferent fibers. Nature. 1980;284:351-353.

43. Laduron P. Axonal transport of opiate receptors in the capsaicin sensitive neurons. Brain Res. 1984;294:157-160.

44. Rosland JH, Tjolsen A, Mrehle B, Hole K. The formalin test in mice: effect of formalin concentration. Pain. 1990;42:235-242.
Journal of Pain Research

\section{Publish your work in this journal}

The Journal of Pain Research is an international, peer reviewed, open access, online journal that welcomes laboratory and clinical findings in the fields of pain research and the prevention and management of pain. Original research, reviews, symposium reports, hypothesis formation and commentaries are all considered for publication.

\section{Dovepress}

The manuscript management system is completely online and includes a very quick and fair peer-review system, which is all easy to use. Visit http://www.dovepress.com/testimonials.php to read real quotes from published authors. 